\title{
Implementasi High Availability Cloud Storage Dengan Metode Replikasi Dan Failover Pada Laboratorium Teknik Informatika
}

\author{
Miftakhdin Kusuma Wijaya ${ }^{* 1}$, Zamah Sari ${ }^{2}$, Mahar Faiqurahman ${ }^{3}$ \\ 1,2,3Teknik Informatika/Universitas Muhammadiyah Malang \\ atfim25@gmail.com ${ }^{*}$, abdzamahsari@gmail.com ${ }^{2}$, maharf@gmail.com ${ }^{3}$
}

\begin{abstract}
Abstrak
Cloud storage merupakan salah satu bentuk dari cloud computing yang terpusat pada media penyimpanan data. Dalam cloud storage ada kemungkinan yang di alami seperti kehilangan data dengan sekala kecil maupun besar, ataupun tidak dapat di akses sama sekali. Kesalahan yang terjadi akibat bencana alam, kesalahan manusia, ataupun alat yang cukup usang. Dari permasalahan tersebut di lakukan backup dan sinkronisasi data untuk menanggulangi permasalahan yang ada. Replikasi adalah proses yang di gunakan untuk menyalin atau mendistribusikan data dari penyedia layanan ke perangkat backup. Replikasi yang di gunakan ada dua yaitu replikasi database MySql dan replikasi data Rsync, dan untuk menjaga agar cloud storage tetap menyediakan sumber daya untuk pengguna dengan menambahkan metode failover. Failover adalah peralihan dari sebuah perangkat penyedia layanan ke perangkat backup ketika mengalami permasalahan yang tidak di inginkan. Pada penelitian ini akan menjelaskan bagaimana cara membangun dan mengimplementasi infrastruktur cloud storage dengan replikasi untuk backup juga sinkronisasi data dan failover untuk memberikan ketersediaan sumber daya layanan untuk pengguna secara realtime.
\end{abstract}

Kata Kunci: Cloud Storage, Rsync, MySql, Failover

\begin{abstract}
Cloud storage is one form of cloud computing but is centered on data storage media. In cloud storage there is the possibility of data loss with small or large scale or cannot be accessed at all. It can happen from natural disasters, human error, or device oldness. From these problems we can do data backup and data synchronization to overcome these problems. Replication is a process that used to copy or distribute data from service providers to backup devices. This replication using two ways, there is replication database using MySql and data replication using Rsync. To keep cloud storage provide resource for user by adding failover. This failover is a transition from a service provider device when having problems to backup device. In this study will explain how to build and implementation cloud storage infrastructure with replication for backup as well as data synchronization and failover to provide real-time availability of service resources for users.
\end{abstract}

Keywords: Cloud Storage, Rsync, MySql, Failover

\section{Pendahuluan}

Cloud Storage merupakan salah satu bentuk dari cloud computing namun terpusat pada media penyimpanan yang dalam pengaksesannya memerlukan jaringan internet maupun intranet. Di cloud storage seseorang di beri hak untuk melakukan akses ke resource yang di miliki oleh penyedia layanan cloud storage. Sehingga pengguna tidak harus membawa storage dengan fisik besar seperti hardisk dan alat penyimpanan lain. Karena cloud storage sudah menyediakan layan penyimpanan dan dapat lebih efisien waktu dan tempat di bandingkan penyimpanan fisik [1].

Owncloud merupakan aplikasi open source yang juga mendukung teknologi cloud computing. Owncloud menyajikan layanan cloud storage seperti dropbox, yaitu layanan penyimpanan dan pengambilan file secara online pada jaringan cloud computing [2]. Di dalam cloud storage memiliki suatu server database, dimana server database ini merupakan tempat penyimpanan seluruh data atau konfigurasi yang di lakukan pada cloud storage.

Dalam cloud storage ada kemungkinan terjadi kerusakan atau kehilangan file dalam skala besar, karena di sebabkan oleh berbagai faktor seperti hardisk bad sector atau hardisk mati. Oleh 
sebab itu pada cloud storage perlu di tambah beberapa backup dan sinkronisasi data untuk mengantisipasi hal-hal tersebut. Replikasi adalah proses yang di gunakan untuk menyalin dan mendistribusikan data pada suatu server database agar dapat terhubung dengan baik antara database satu ke database lainnya. Untuk mengoptimalkan kerja suatu replikasi di butuhkan adanya failover [3].

Failover adalah peralihan ke sebuah perangkat komponen atau server cadangan saat server utama mengalami gangguan. Dengan menggunakan failover kita dapat mengakses data yang di simpan pada saat server utama mengalami gangguan [4].

Failover clustering merupakan salah satu bentuk failover yang menyediakan solusi high availability server dimana jika terjadi kegagalan pada sistem hardware seperti power supply mati yang menyebabkan server mati total maka server lain anggota cluster yang akan mengambil alih fungsi dari server yang mati, sehingga pengguna tidak mengetahui terjadinya kegagalan pada server karena proses yang dilakukan pada server yang gagal atau mati akan dilanjutkan oleh server backup [5]. Failover memiliki beberapa metode dalam menangani kegagalan sistem atau komponen. Warm Stanby merupakan salah satu metode failover dimana metode ini membutuhkan replikasi dan failover otomatis untuk meggantikan komponen atau service utama yang gagal. Solusi ini dipakai untuk melalukan redudansi hardwere dan softwere. Di dalam metode ini server utama secara teratur akan melakukan replikasi ke server cadangan. Ketika server utama mengalami kegagalan server cadangan akan menggantikan peran server utama berdasarkan replikasi terakhir yang tercatat dari server utama sebelum server utama mengalami kegagalan [6].

Karena berhubungan dengan Laboraturium Teknik Informatika, yang membutuhkan tempat penyimpanan untuk menyimpan dan mendristribusikan data secara flexible dari pihak administrasi ke mahasiswa teknik informatika maupun, dari pihak mahasiswa teknik informatika ke administrasi, dan juga membutuhkan system back up, dimana ketika server utama mati server backup akan mengambil alih peranan serverutama. Dalam penelitian ini akan di implementasikan high availability cloud storage dengan metode replikasi dan failover agar memberi kinerja yang maksimal untuk cloud private storage pada Laboratorium Teknik Informatika.

\section{Metode Penelitian}

Dalam perancangan ini saat kondisi di Lab Teknik Informatika belum tersedia back up data dan kontrol server ketika server utama mengalami gangguan. Efek dari kondisi di atas tidak menutup kemungkinan server tidak dapat di akses, server mati total dan bahkan kehilangan data pengguna atau user. Dengan permasalahan di atas di buatlah high availability cloud storage di mana ketika server mengalami gangguan akan di alihkan ke server cadangan dengan bantuan failover. Dan saat server utama mengalami gangguan peran server cadangan menangani data yang direquest oleh pengguna dengan bantuan replikasi. Gambar 1 merupakan arsitektur cloud storage yang berdasarkan perancangan sistem yang telah di buat dan di butuhkan sebelumnya

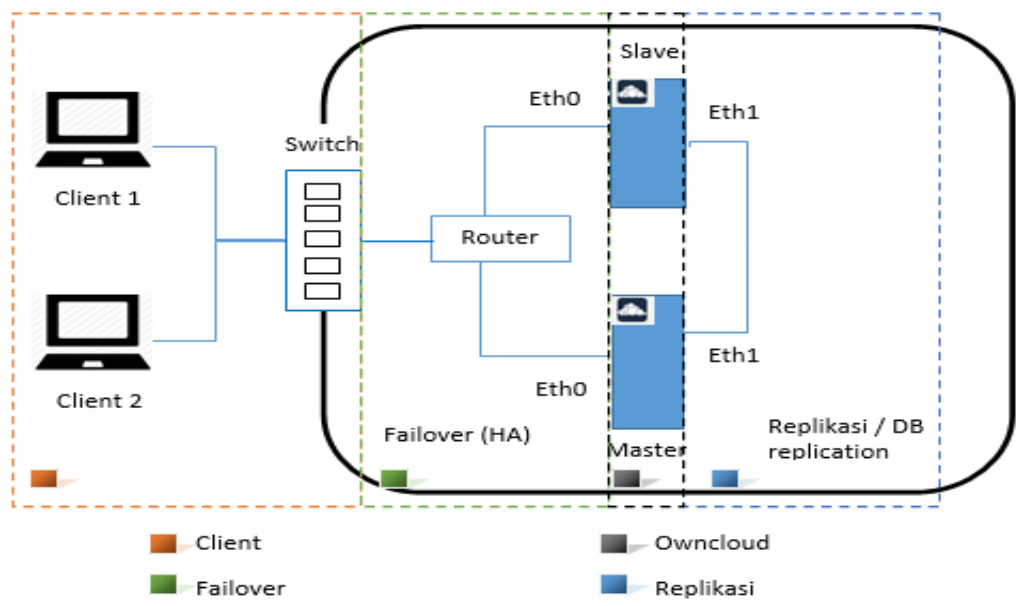

Gambar 1. Arsitektur Cloud Storage

Pada Gambar 2 merupakan alur perancangan sistem keseluruhan yang akan di buat dengan urutan penerapan yang terdapat pada asitektur cloud storage pada Gambar 1.

REPOSITOR, Vol. 2, No. 2, Februari 2020: 165-176 


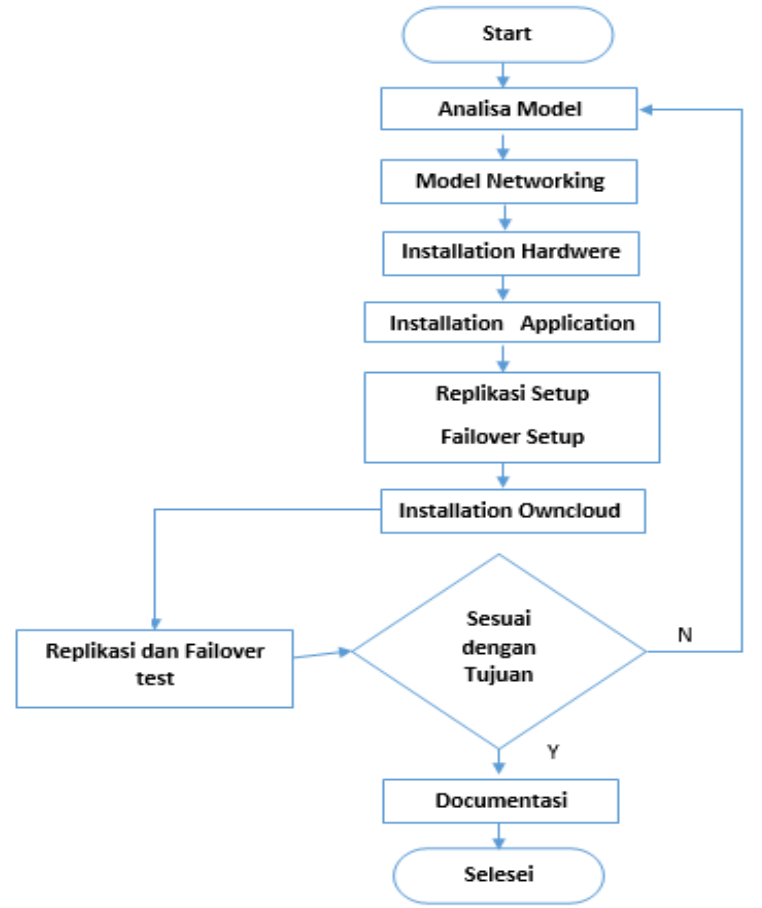

Gambar 2. Alur Perancangan Sistem

Gambar 2 merupakan alur proses replikasi database pada arsitektur cloud storage. Ketika server master mendapat instruksi create user maka akan dilanjutkan mereplikasi ke server slave. Dan dan dalam setiap waktu akan selalu ada pengecekan ketika server master mangalami perubahan, dan ketika server mengalami perubahan replikasi akan berjalan kembali dan di sinkronkan ke server slave, jika tidak ada perubahan data replikasi selesai.

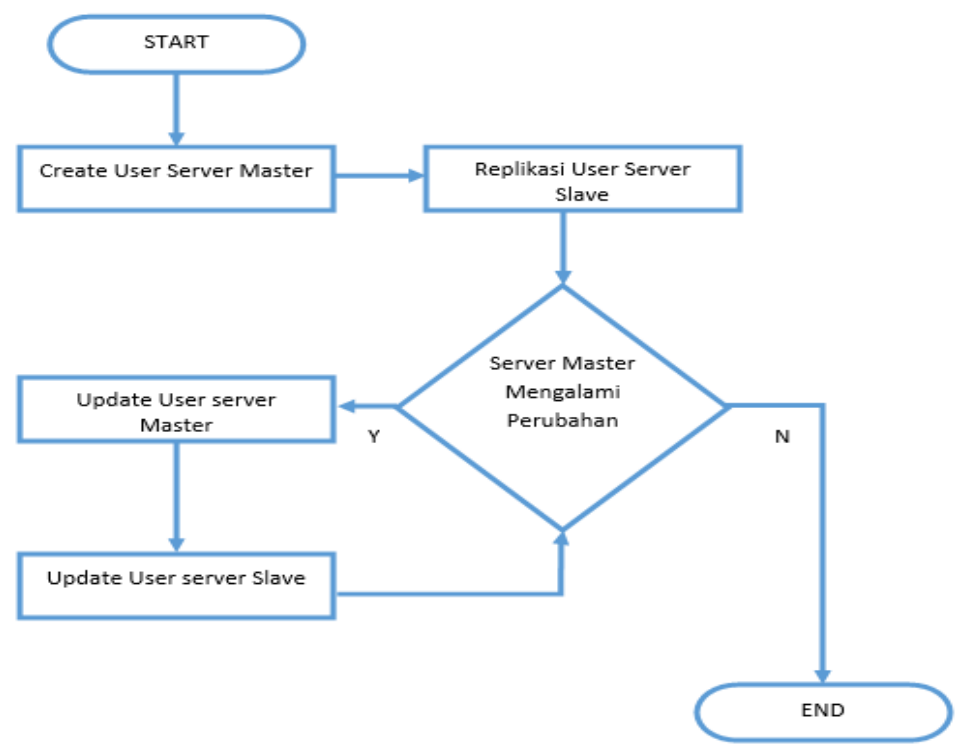

Gambar 3. Alur Proses Replikasi Database (MySql)

Gambar 3 merupakan alur proses replikasi database pada arsitektur cloud storage. Ketika user memberikan instruksi untuk menambahkan file ke dalam server master, maka data yang sudah berhasil ditambahkan ke dalam server master akan di kirim atau di teruskan ke server slave. Proses replikasi Rsync menggunakan cronjob untuk memberikan waktu realtime, waktu minimal yang di butuhkan cronjob adalah setiap 1 menit dalam 1 jam untuk melakuan perintah replikasi. 


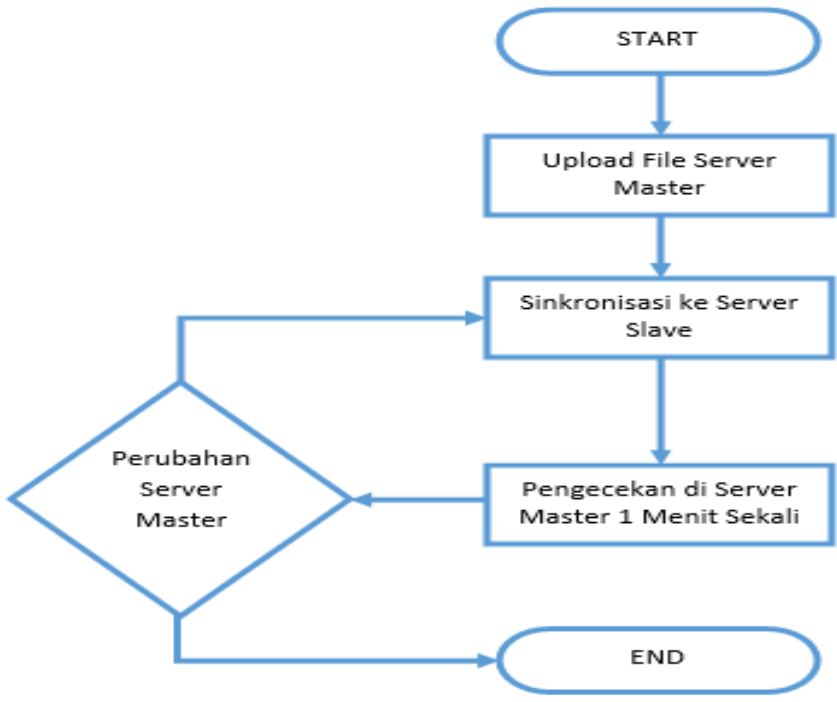

Gambar 4. Alur Proses Replikasi Data (rsync)

Gambar 4 merupakan alur proses replikasi database pada arsitektur cloud storage. Ketika server master mati maka akan di lakukan failover ke server slave. Server slave akan mengambil alih semua beban dan request dari client. Ketika server master aktif, failover akan di alihkan kembali pada prioritas terbesar yaitu server master.

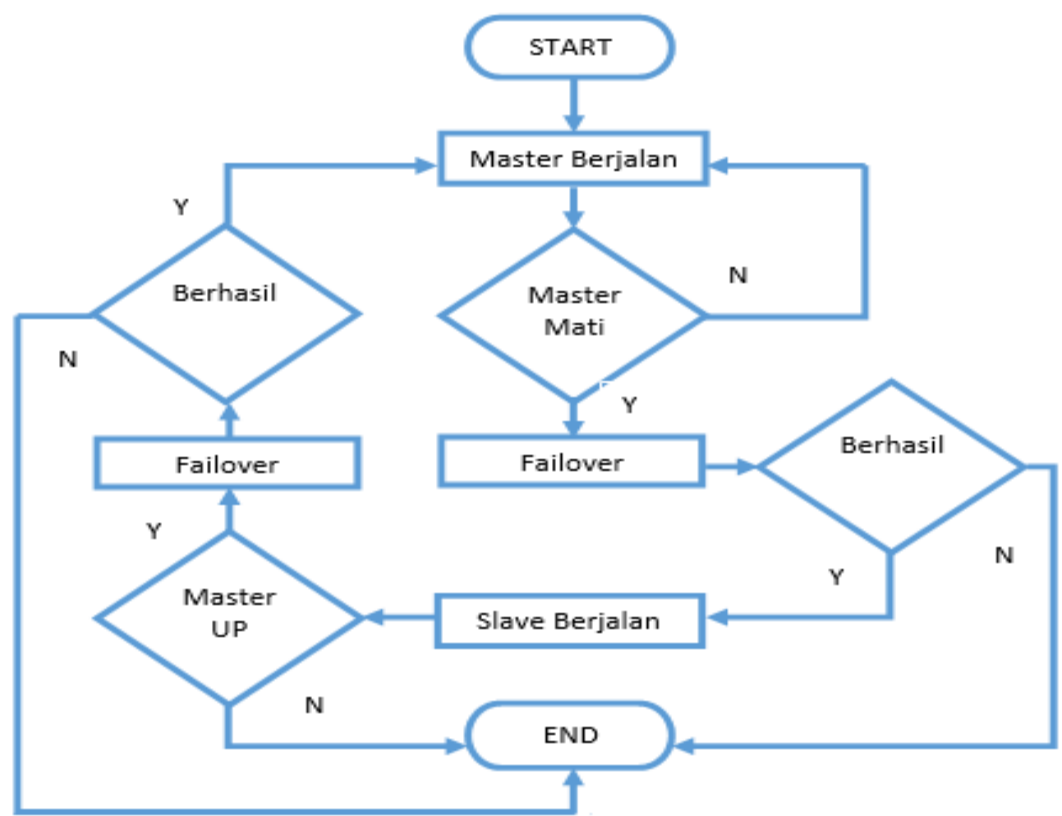

Gambar 5. Alur Proses Failover

Pada Gambar 5, dijelaskan tentang proses kerja dari failover. Ketika server master mati maka akan di lakukan failover ke server slave. Server slave akan mengambil alih semua beban dan request dari client. Ketika server master aktif, failover akan di alihkan kembali pada prioritas terbesar yaitu server master.

\section{Hasil Penelitian dan Pembahasan}

\subsection{User Interface}

Gambar 6 dan Gambar 7 merupakan tampilan cloud storage yang di akses oleh pengguna. Pengguna hanya dapat mengelola cloud mereka menggunakan user dan password pada Owcloud di web browser.

REPOSITOR, Vol. 2, No. 2, Februari 2020: 165-176 


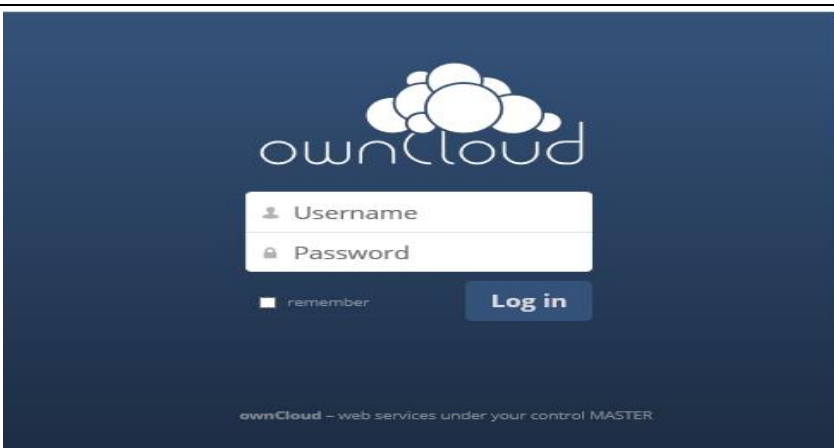

Gambar 6. Interface Login

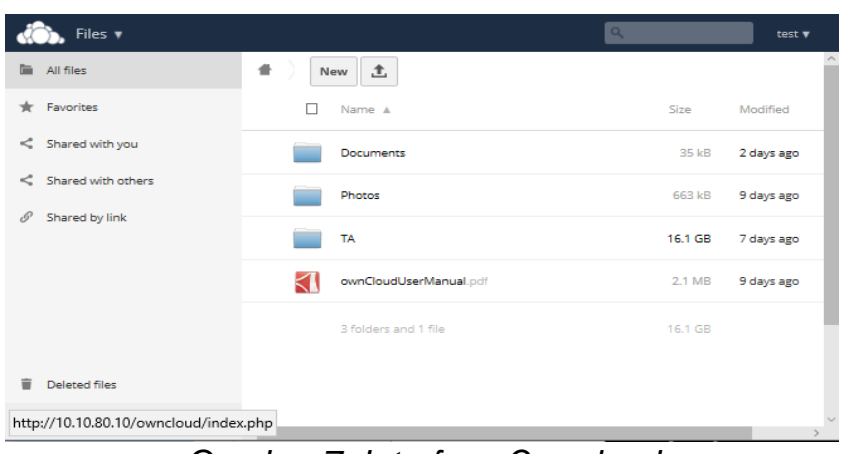

Gambar 7. Interface Owncloud

\subsection{Pengujian Fungsional}

Pengujian pertama yaitu pengujian failover menggunakan alamat Owncloud dengan melakukan login IP virtual dan cek ping IP address server master dan IP virtual.

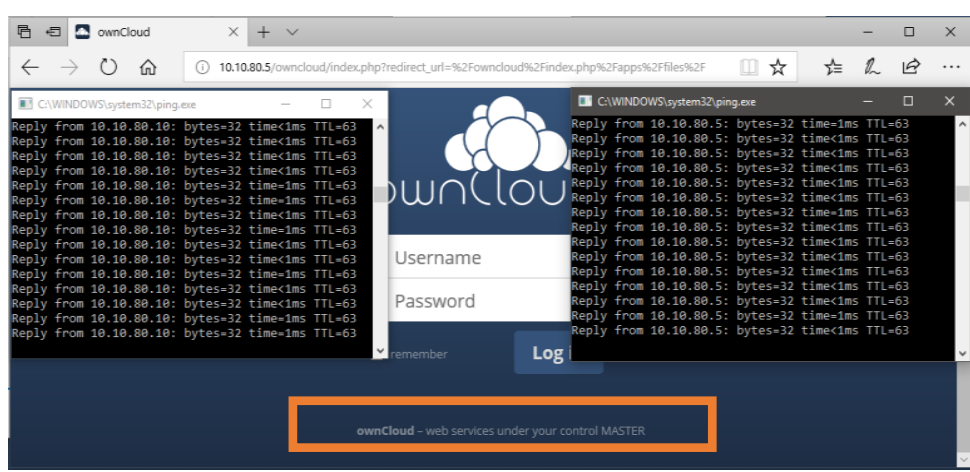

Gambar 8. Pengujian Owncloud saat Master Up

Terlihat pada Gambar 8, IP virtual dengan alamat 10.10.80.5/owncloud mengarahkan akses dari user ke server master, karena server master memiliki prioritas lebih besar dari slave.

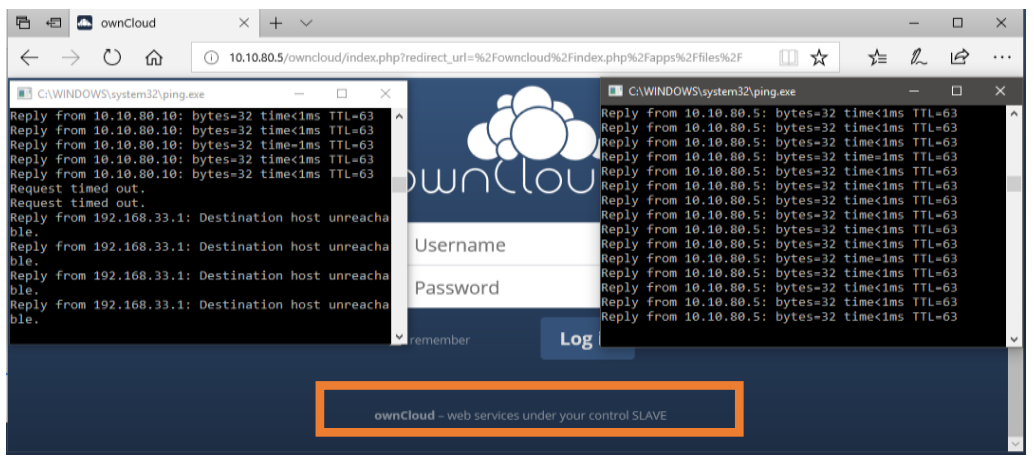

Gambar 9. Pengujian Owncloud saat Master Down 
Terlihat pada Gambar 9 IP virtual dengan alamat 10.10.80.5 /owncloud mengarahkan akses dari user ke server slave. Karena server master yang memiliki prioritas tertinggi tidak dapat di akses maka, server slave yang memiliki prioritas di bawah server master yang akan menggantikan peran master.

Setelah pembuatan user-user pada server master melalui Owncloud menggunakan ID admin terlihat user1, user2, user3, selanjutnya melihat pada Owncloud di server slave dengan menggunakan login ID admin.

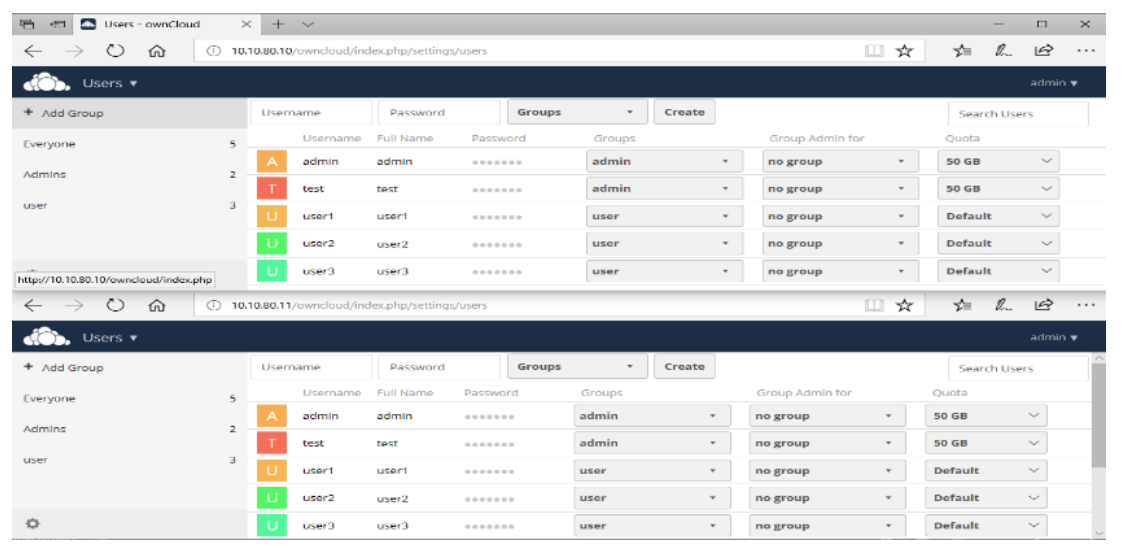

Gambar 10. User Sudah Replikasi

Sebelum pengujian dilakukan perlu dipersiapkan beberapa file yang berukuran berbeda dan di upload pada owncloud terlebih dahulu. Di pengujian ini menggunakan user test pada owncloud yang sudah dibuat sebelumnya, seperti pada Gambar 10.

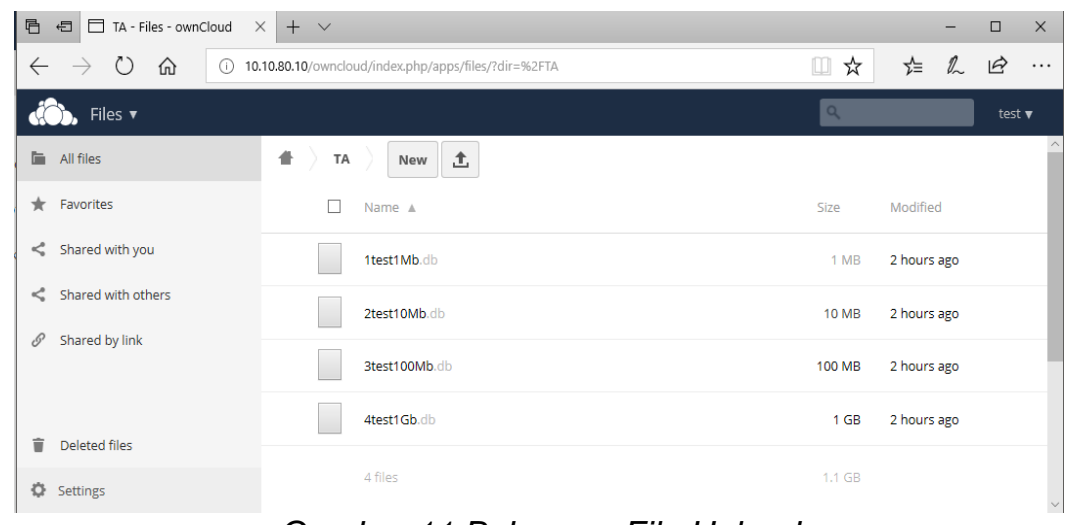

Gambar 11 Beberapa File Upload

Gambar 11 di atas adalah beberapa file yang sudah di upload ke dalam server master dan siap untuk di lakukan pengujian.

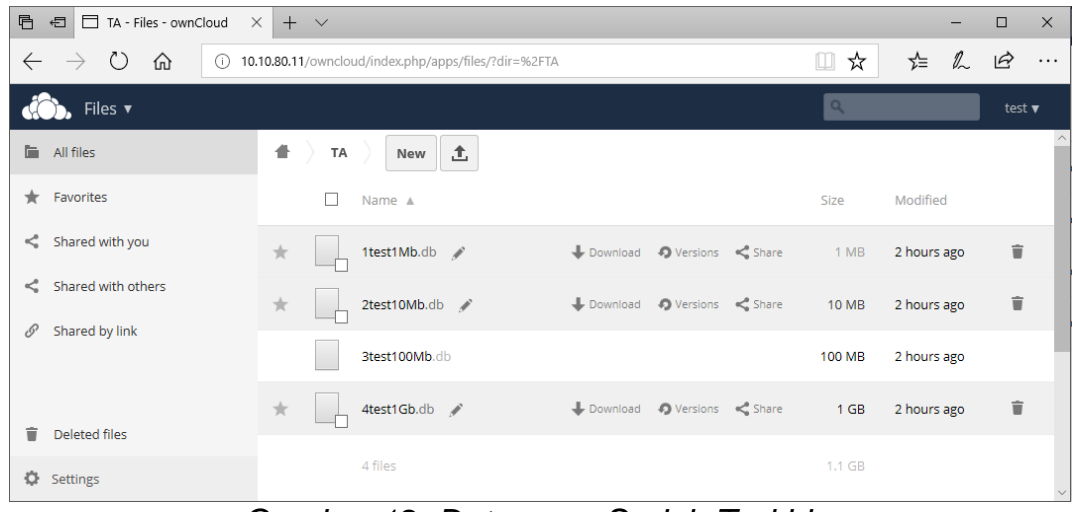

Gambar 12. Data yang Sudah Terkirim

REPOSITOR, Vol. 2, No. 2, Februari 2020: 165-176 
Gambar 12 merupakan hasil dari replikasi data menggunkan rsync, dapat dilihat jumlah dan besar file sama dengan jumlah atau besar file sebelum dilakukan replikasi pada server master.

\subsection{Pengujian Performasi}

Pengujian performansi failover dengan mematikan server master untuk melihat perpindahan master ke slave dan juga diberi beban pada server master, beban yang dimaksud, yaitu download data 5GB dengan 5 kali percobaan yang terdapat pada Tabel 1.

Tabel 1. Tabel Failover

\begin{tabular}{cccc}
\hline $\begin{array}{c}\text { Percobaan } \\
\text { Master Down }\end{array}$ & $\begin{array}{c}\text { Down time } \\
\text { Failover }\end{array}$ & $\begin{array}{c}\text { Ping Time } \\
\text { Sebelum }\end{array}$ & $\begin{array}{c}\text { Ping Time } \\
\text { Sesudah }\end{array}$ \\
\hline 1 & 1 RTO & $<5 \mathrm{~ms}$ & $<1 \mathrm{~ms}$ \\
2 & 1 RTO & $<4 \mathrm{~ms}$ & $<1 \mathrm{~ms}$ \\
3 & 1 RTO & $<7 \mathrm{~ms}$ & $<1 \mathrm{~ms}$ \\
4 & 1 RTO & $<4 \mathrm{~ms}$ & $<1 \mathrm{~ms}$ \\
5 & 1 RTO & $<5 \mathrm{~ms}$ & $<1 \mathrm{~ms}$ \\
\hline
\end{tabular}

Pada Tabel 1 hasil dari failover sebanyak lima kali pengujian, down time failover adalah suatu proses failover untuk perpindahan antara master ke slave hasil tabel diambil dari proses ping IP virtual dengan alamat IP 10.10.80. Sebelum terjadi kegagalan dan dilakukan failover ke server slave, ping time kurang lebih $5 \mathrm{~ms}-7 \mathrm{~ms}$ dikarenakan server master memiliki beban download dan ping time sesudah dilakukan failover kurang lebih $1 \mathrm{~ms}$ pada saat dilakukan failover, server slave tidak memiliki beban apapun, seperti grafik pada Gambar 13 dan Gambar 14.

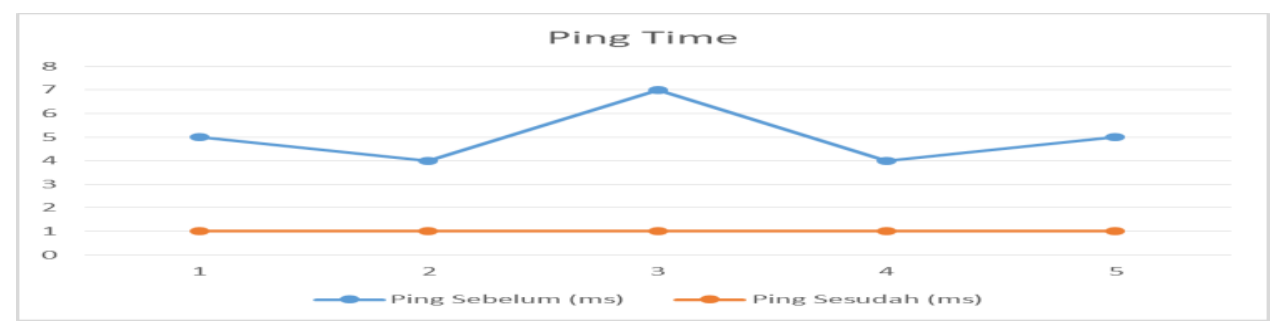

Gambar 13. Grafik Ping Time Failover

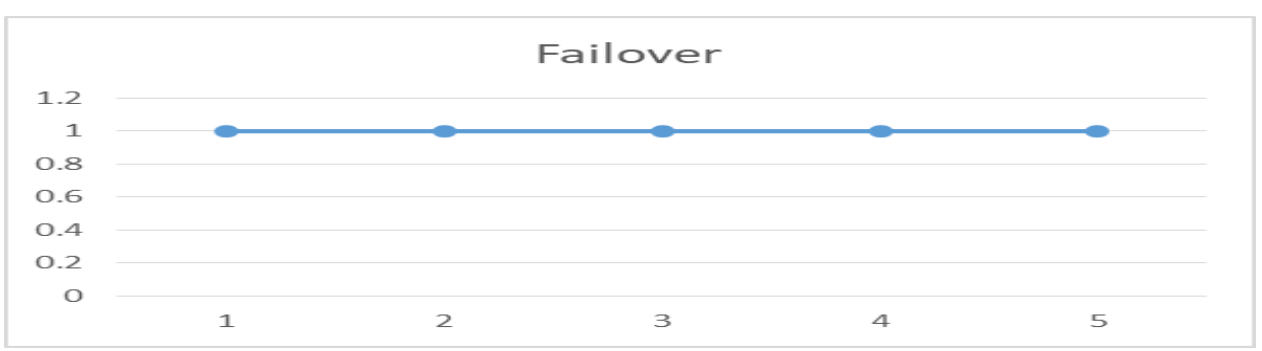

Gambar 14. Grafik RTO Failover

Pengujian failback ini di lakukan sebanyak 5 kali percobaan untuk mendapat data delay failover failback, dan ping time sebelum dan sesudah, dengan beban download file 10GB di server master dan server slave.

Tabel 2. Pengujian Failback

\begin{tabular}{cccc}
\hline $\begin{array}{c}\text { Percobaan } \\
\text { Master Down }\end{array}$ & Failback & $\begin{array}{c}\text { Ping Time } \\
\text { Sebelum }\end{array}$ & $\begin{array}{c}\text { Ping Time } \\
\text { Sesudah }\end{array}$ \\
\hline 1 & 1 RTO & $<1 \mathrm{~ms}$ & $<1 \mathrm{~ms}$ \\
2 & 1 RTO & $<1 \mathrm{~ms}$ & $<1 \mathrm{~ms}$ \\
3 & 1 RTO & $<1 \mathrm{~ms}$ & $<1 \mathrm{~ms}$ \\
4 & 1 RTO & $<1 \mathrm{~ms}$ & $<1 \mathrm{~ms}$ \\
5 & 1 RTO & $<1 \mathrm{~ms}$ & $<1 \mathrm{~ms}$ \\
\hline
\end{tabular}

Implementasi High Availability Cloud Storage... Miftakhdin Kusuma Wijaya, Zamah Sari, Mahar Faiqurahman 
Tabel 2, merupakan beberapa pengujian yang di lakukan untuk melihat berberapa failback, ping time pada sistem cloud storage yang telah di buat. Failback merupakan perpindahan kembali dari slave ke server ketika server utama UP kembali. Dalam Tabel 2, pengujian dilakukan pada IP server master dan IP virtual. Dilihat ping time sebelum dan sesudah failback tidak mengalami perubahan dikarenakan, proses download yang terjadi pada server master telah terputus, maka trafik kembali kepada kondisi normal tanpa beban. Ping time sebelumnya adalah melakukan ping sebelum terjadinya failback dan ping time sesudah adalah ping sesudah failback, seperti pada Gambar 15.

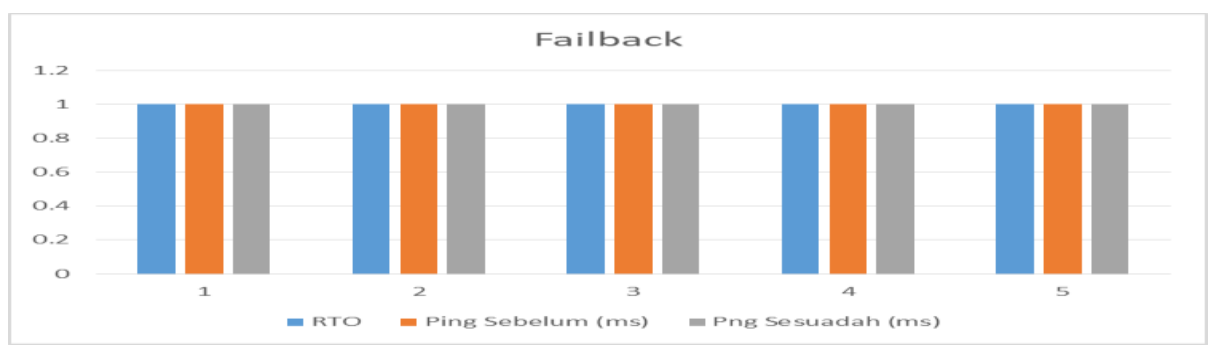

Gambar 15. Grafik Failback

Pengujian performansi replikasi ini menggunakan Rsync untuk melihat kecepatan transfer saat terjadinya replikasi, pengujian di sini menggunakan 5 variasi data dari 1Mb sampai 10GB

Pada Tabel 3 serta Gambar 16 dan Gambar 17, menunjukkan kecepatan transfer menggunakan rsync, proses transfer dengan rsync berjalan satu per satu mulai dari atas, dan setelah dilakukan transfer, diperlukan berapa detik untuk dapat mentransfer beberapa file yang berbeda ukuran.

Tabel 3. Proses Replikasi Data atau File

\begin{tabular}{cccc}
\hline Data & Ukuran Data & Kecepatan Transfer & Delay Pengiriman \\
\hline 1 & $1 \mathrm{Mb}$ & $60.55 \mathrm{MB} / \mathrm{s}$ & $00: 00: 00$ \\
2 & $10 \mathrm{Mb}$ & $66.23 \mathrm{MB} / \mathrm{s}$ & $00: 00: 00$ \\
3 & $100 \mathrm{Mb}$ & $70.32 \mathrm{MB} / \mathrm{s}$ & $00: 00: 01$ \\
4 & $1 \mathrm{~Gb}$ & $75.94 \mathrm{MB} / \mathrm{s}$ & $00: 00: 13$ \\
5 & $5 \mathrm{~Gb}$ & $71.00 \mathrm{MB} / \mathrm{s}$ & $0: 01: 12$ \\
6 & $10 \mathrm{~Gb}$ & $35.56 \mathrm{MB} / \mathrm{s}$ & $0: 03: 44$ \\
\hline
\end{tabular}

Tabel 3 adalah hasil dari replikasi data menggunakan rsync dengan ukuran data yang berbeda. Data yang digunakan adalah data binary dengan asumsi, saat proses replikasi kondisi trafik jaringan tidak memiliki beban.
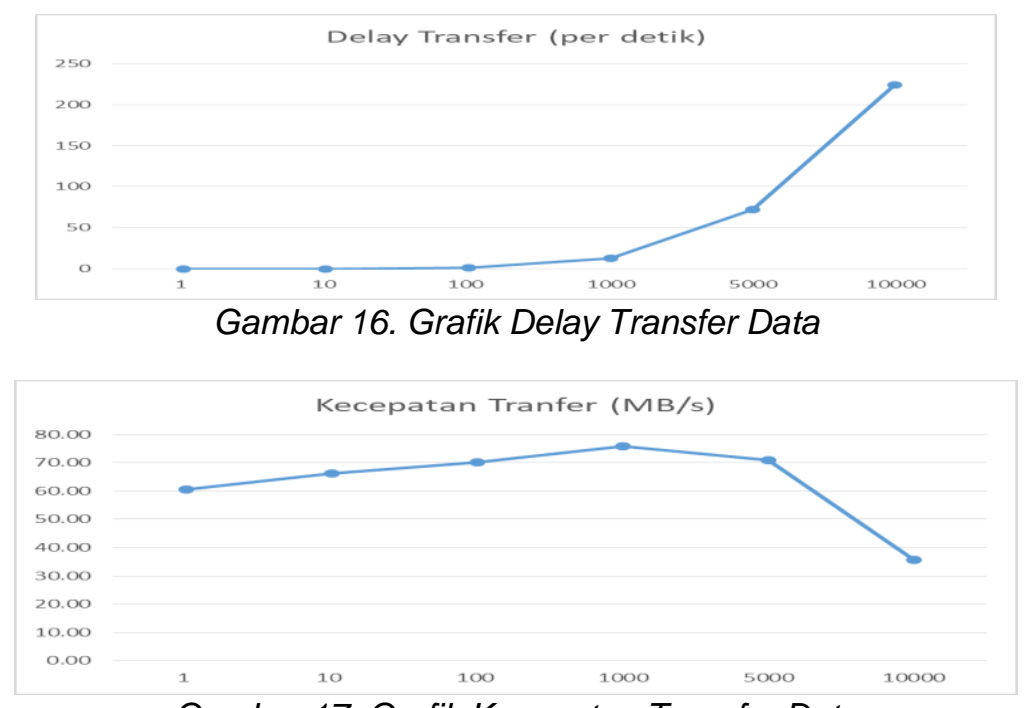

Gambar 17. Grafik Kecepatan Transfer Data

REPOSITOR, Vol. 2, No. 2, Februari 2020: 165-176 
Pengujian replikasi selanjutnya menggunakan beban pada saat terjadinya replikasi. Beban yang di maksut yaitu pada saat ada proses download data yang di lakukan pengguna dan ketika proses replikasi berjalan. Pada Gambar 18 adalah proses pengujian pada saat trafik sibuk dengan replikasi data 5GB.

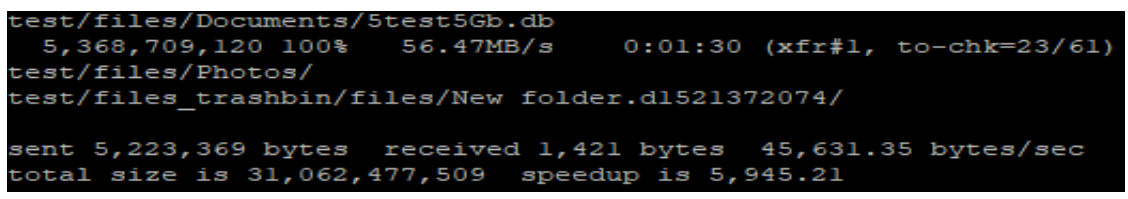

Gambar 18. Proses Transfer Dengan Beban Trafik Jaringan

Gambar 18 merupakan hasil replikasi data dengan beban 5GB download, terlihat pada Tabel 3. Dimana kecepatan replikasi data $5 \mathrm{~GB}$ pada saat tidak ada beban adalah $71.00 \mathrm{MB} / \mathrm{s}$ dengan perbandingan kecepatan replikasi $5 \mathrm{~GB}$ pada saat memiliki beban sekitar $65.47 \mathrm{MB} / \mathrm{s}$.

\subsection{Pengujian Download Data}

Pada pengujian ini dilakukan dengan cara mengunduh data dari Owncloud menggunakan IP virtual, file yang di download sebesar $10 \mathrm{~Gb}$ agar pada proses pengunduhan memiliki waktu yang cukup untuk melihat kecepatan download. Pengujian yang di gunakan dengan memberi variasi pada jumlah user yang download secara bersamaan.

Tabel 4. Pengujian Download Data

\begin{tabular}{ccc}
\hline Pengujian & Jumlah User & Kecepatan Download \\
\hline 1 & 1 User & $+10.209 \mathrm{~KB} / \mathrm{s}$ \\
2 & 2 User & $+5.210 \mathrm{~KB} / \mathrm{s}$ \\
3 & 3 User & $+3.120 \mathrm{~KB} / \mathrm{s}$ \\
4 & 4 User & $+2.120 \mathrm{~KB} / \mathrm{s}$ \\
5 & 5 User & $+1.812 \mathrm{~KB} / \mathrm{s}$ \\
\hline
\end{tabular}

Tabel 4 adalah pengujian download data 10 GB dengan variasi user dari 1 user sampai 5 user. Grafik pada Gambar 19 pada pengujian download ini menggunakan IDM agar speed download yang diperoleh lebih maksimal, dengan pengujian secara bertahap. serta didapatkan range download pada saat melakukan proses download.

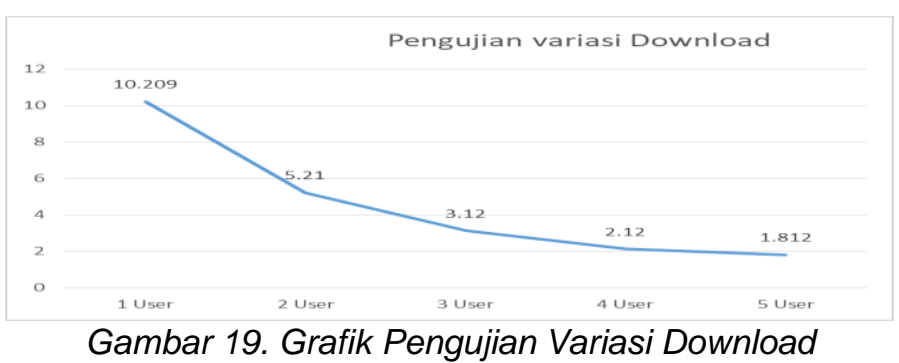

Dalam setiap sistem pasti memiliki beberapa kelemahan, pada sistem yang di buat pada penelitian ini memeliki kelemahan saat download berlangsung. Gambar 20 merupakan pengujian kelemahan sistem yang di buat.

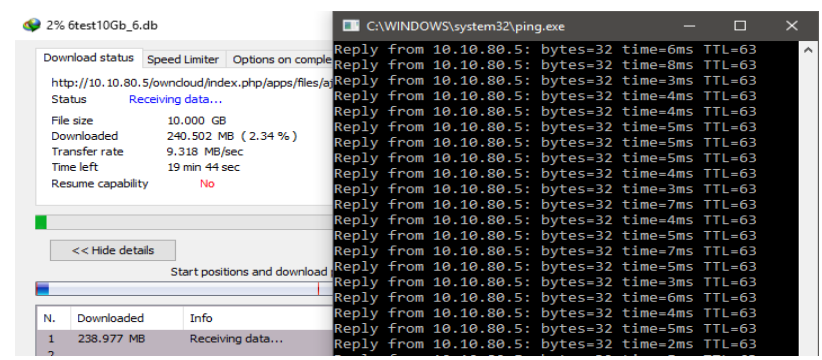

Gambar 20. Download IDM Master UP 
Gambar 20 adalah pengujian dengan skenario ketika server master UP dan dilakukan download data lewat IP virtual.

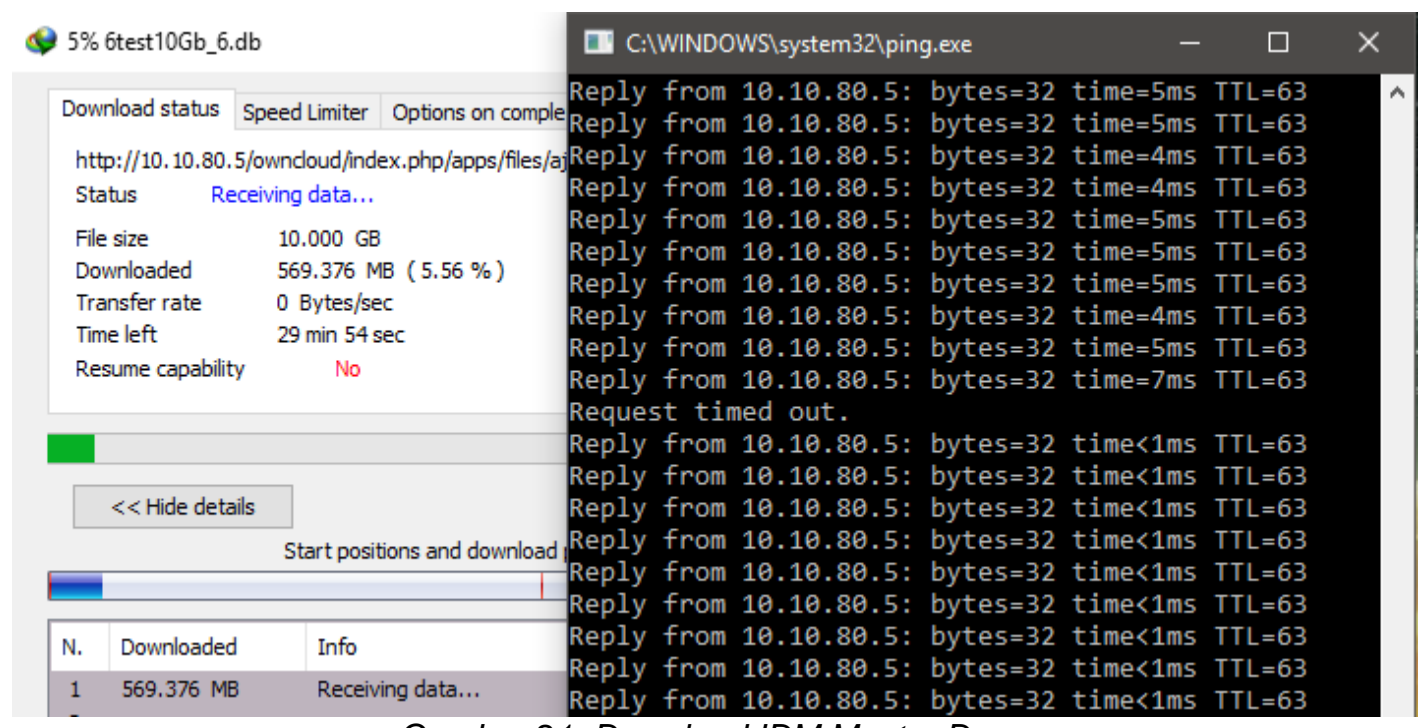

Gambar 21. Download IDM Master Down

Gambar 21 adalah pengujian dengan skenario saat melakukan proses download pada saat server master mengalami kegagalan, dan di lakukan failover ke server slave. Proses failover bisa di lihat pada saat ping ketika mengalami request time out dan ping turun menjadi $1 \mathrm{~ms}$.

\section{Kesimpulan}

Dari penelitian yang telah dilakukan ada beberapa kesimpulan yang dapat diambil dari seluruh percobaan dan pengujian pada sistem yang telah dibangun yang berjudul "Implementasi High Availability Cloud Storage Dengan Metode Replikasi Dan Failover Pada Laboratorium Teknik Informatika", dapat disimpulkan sebagai berikut:

1. Penggunaan metode failover efektif diterapkan pada infrastrukur server private cloud storage terbukti berhasil diterapkan dengan baik saat menangani kegagalan sistem, dibuktikan pada saat server master mengalami kegagalan dan client atau pengguna layanan masih bisa mengakses melalui server slave, dan ketika server master aktif kembali sistem berhasil mengembalikan ke server master.

2. Penerapan sistem Owncloud pada server private cloud storage berjalan dengan baik saat melayani dan membuat account dari client, kemudian client berhasil melakukan upload data juga download data.

3. Pengujian failover dan failback dengan di berikan beban pada server master berjalan dengan baik pada proses perindahan.

4. Penerapan replikasi pada private cloud storage Owncloud menggunakan mysql tereplika dengan baik, replikasi data menggunakan Rsync meiliki transfer rate cukup kecil yakni $1 \mathrm{~GB}$ /13 detik dan 10GB/3:44 menit.

5. Pengujian download file pada IP virtual dengan skenario mematikan server master mendapatkan kendala, karena ketika server master mati proses download akan berhenti walaupun sudah ada perpindahan failover.

\section{Saran}

Adapun saran dari penulis yang dapat di gunakan untuk pengembangan system ini untuk menjadi lebih baik, antara lain:

1. Perlu dibuat load balancer pada cloud storage dengan tujuan memaksimalkan akses upload dan download dari user atau pengguna layanan

2. Perlu adanya tambahan sistem keamanan dengan tujuan mengamankan segala transaksi atau pengiriman file

3. Penambahan sitem monitoring kecepatan, data yang di pakai atau yang di gunakan dan sisa ruang yang bisa di pakai. 


\section{Referensi}

[1] T. A. Nugroho, "Perancangan Private Cloud Storage Menggunakan ownCloud ( Studi Kasus di Program Studi Magister IImu Lingkungan Universitas Sebelas Maret ) Perancangan Private Cloud Storage Menggunakan ownCloud ( Studi Kasus di Program Studi Magister IImu Lingkungan Unive," 2014.

[2] T. R. Febriani, "Implementasi Dan Analisa Sistem Failover Virtual Computer Cluster," 2011.

[3] C. Engelmann, "Active/active replication for highly available HPC system services," Proceedings - First International Conference on Availability, Reliability and Security, ARES 2006, vol. 2006, no. 8, pp. 639-645, 2006.

[4] E. S. Purwanto, "Perbandingan Strategi Replikasi Pada Sistem Basis Data Terdistribusi," Jurnal Informatika, pp. 1-8, 2012.

[5] S. M. Parasian D. P. Silitonga, "Replikasi Basis Data Pada Sistem Pengolahan Data Akademik," Jurnal TIME, Vol. III No 1 : 32-36, 2014 ISSN : 2337 - 3601, vol. III, no. 1, pp. 32-36, 2014.

[6] N. Purnomo, "Pemanfaatan Failover Cluster Server Guna Recovery Sistem Pada Pt.Lintas Data Prima," Naskah Publikasi diajukan, 2012. 
REPOSITOR, Vol. 2, No. 2, Februari 2020: 165-176 